\title{
DROGAS NA ADOLESCÊNCIA: UMA ESTRATÉGIA DE EDUCAÇÃO EM SAÚDE NA ESCOLA
}

\author{
Pâmela dos Santos Rocha ${ }^{1}$ \\ Shirlley de Souza Silva² \\ Janielly Bezerra Raimundo ${ }^{3}$
}

\section{INTRODUÇÃO}

O consumo de drogas vem crescendo mundialmente e a população mais atingida são os jovens, isso tem sido uma questão que vem afligindo a sociedade contemporânea (TAVARES, BÉRIA; LIMA, 2001). Diante disso, a escola encontra um novo desafio e, assim, educar para a prevenção é a melhor alternativa para enfrentar o consumo entre os estudantes (GIL et al. 2008). Em estudos epidemiológicos indicam serem os adolescentes uma população de alta incidência para o consumo de drogas, acreditam que existe uma associação às modificações físicas, comportamentais, emocionais e mesmo, por estarem sujeitos a farta exposição a riscos característicos da idade, seguidos pelas fraquezas das redes de apoio social que nem sempre se estabelecem de forma harmoniosa na adolescência (MALTA et al. 2011).

As drogas ilícitas causam maior temor da sociedade, e recebem maior atenção das famílias e da escola, quando, na verdade, são as lícitas, como o álcool, que apresentam maior incidência de consumo ao ser comparada com as demais substâncias, de fato tal licitude não se restringe à legislação, mas extrapola-se para as ações parentais que não percebem no consumo etílico o perigo estampado (NASCIMENTO; AVALLONE, 2013).

A escola tem papel fundamental no desenvolvimento do adolescente, pois contribui para a formação global do jovem e consequentemente da sociedade. A prevenção ao uso deve ser promovida durante toda a vida da criança, assim o papel da escola na prevenção é educar

\footnotetext{
${ }^{1}$ Graduação em Terapia Ocupacional - Universidade Estadual de Ciências da Saúde de Alagoas - UNCISAL.Email: to.pamelarocha@gmail.com

${ }^{2}$ Graduação em Terapia Ocupacional - Universidade Estadual de Ciências da Saúde de Alagoas - UNCISAL. Email:toshirlley@gmail.com

${ }^{3}$ Graduação em Terapia Ocupacional - Universidade Estadual de Ciências da Saúde de Alagoas - UNCISAL. Email: janiellybezerra@gmail.com
} 
e ajudá-los a buscarem e desenvolverem sua identidade e subjetividade, promover e integrar a educação intelectual e emocional (SOARES; JACOBI, 2013).

A efetivação da saúde escolar como política pública de promoção da saúde e de garantia de qualidade de vida exige coordenação e planejamento intersetoriais, com definição de orçamento adequado e coerente com o discurso construído acerca de uma noção ampliada de saúde e de uma educação integral (LEVY et al.1997). No qual requer a definição de iniciativas interdisciplinares selecionadas a partir de diagnóstico local da realidade, com identificação dos problemas reais e das soluções viáveis em cada escola de forma a contribuir para a autonomia e o apoderamento dos sujeitos diante dos direitos fundamentais relacionados ao tema da saúde escolar (MOREIRA et al. 2006).

A escola, por compor um centro de ensino-aprendizagem, convivência e crescimento importante, é nela que se adquirem valores vitais e fundamentais. Sendo o lugar ideal ao desenvolvimento de ações educativas na promoção à saúde, atuando com grande influência, pois crianças e adolescentes estão em fase de desenvolvimento do seu comportamento, conhecimento, o senso de responsabilidade e a capacidade de observar, pensar e agir (CASEMIRO et al. 2014).

\section{METODOLOGIA}

Trata-se de um relato de experiência resultado do Estágio Obrigatório do curso de Terapia Ocupacional, cuja disciplina era Terapia Ocupacional em Saúde Coletiva. O local realizado foi a Escola Municipal de Ensino Fundamental Profo Antídio Vieira, Situada no bairro do Pontal da Barra, em Maceió, capital do estado de Alagoas, litoral do nordeste brasileiro. Esse bairro possui uma população de 2.478 habitantes distribuídos em 915 domicílios permanentes em uma região de restinga, entre a Lagoa Mundaú e o Oceano Atlântico.

A abundância de recursos hídricos favorece o desenvolvimento de atividades pesqueiras e as belezas naturais atraem turistas de diversos lugares, que aproveitam os passeios de barco, as comidas típicas, as 
paisagens e o artesanato local. Participação de homens na produção de uma renda típica na comunidade. Em virtude da importância do artesanato local e do ambiente paisagístico do Pontal da Barra para o desenvolvimento turístico do Estado de Alagoas (MARTINS et al .2016), o público alvo foram alunos do

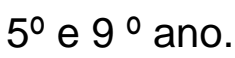

A escolha do local para intervenção se deu por meio do processo de territorialização e mapeamento, identificando grupos, famílias e indivíduos expostos a riscos diários, onde foi possível verificar uma quantidade significativa de usuários de álcool e drogas e, sobretudo, pela solicitação da assistente social da escola, visto que, o uso das drogas representa a realidade de muitos pais dos alunos e da preocupação que muitos pré-adolescentes e adolescentes iniciam o primeiro contato da droga nessa fase, dessa forma, levando em consideração os aspectos culturais, econômicos e sociais dos alunos, suas concepções nessa fase de formação de idéias surgiu o interesse de promover as oficinas.

As intervenções se deram em quatro momentos utilizando-se de dinâmicas e construções coletivas do conhecimento entre a teoria e prática e os recursos utilizados foram de baixo custo como bola de assopro e música, é importante ressaltar que durante as intervenções o objetivo era passar as informações da melhor forma possível e assim as crianças puderam aprender de forma divertida.

\section{RESULTADOS E DISCUSSÃO}

O estudo da prevenção relacionada ao uso de drogas e dirigida aos adolescentes tem natureza interdisciplinar, sendo necessário levar em consideração três tópicos: a droga utilizada, o contexto histórico e cultural e a classe social que $o$ adolescente pertence.

A escola como é o local de acesso direto aos jovens, é em todo o mundo o local privilegiado para programas de prevenção dirigidos aos jovens. As ações de prevenção representam um desafio constante, na busca estratégica que chame atenção de pré- adolescentes e adolescentes no que refere as questões sobre drogas, haja vista que temos ainda muito poucas ações educacionais quando se trata da temática no espaço Escolar. Falar 
sobre drogas é sempre delicado. Geralmente, as discussões são inflamadas por juízos de valor, pré-julgamentos ou preconceitos que levam as pessoas a perceber a problemática, essa temática deve ser adequadamente debatida e trabalhada no ambiente escolar, para ter uma melhor condição de enfrentar este problema e previni-lo, promovendo a saúde de todos os sujeitos que vivenciam o cotidiano escolar, seja os educadores, profissionais de diferentes áreas de conhecimento, alunos ou familiares.

Para a Atenção Básica em Saúde, por a escola ter estes aspectos possibilita uma estreita relação entre saúde e educação com o objetivo de fortalecer uma prática intersetorial como instrumento para tecer redes de cuidado. A partir das informações, as pessoas poderão tomar decisões conscientes e bem fundamentadas sobre as drogas. $\mathrm{E}$ a escola pode oferecer e favorecer a prática de projetos de vida, tornando-se um espaço de participação, realização, conscientização e criação de novas práticas de respeito, acolhimento e inclusão daqueles que vivem numa condição de dependência e de sofrimento.

Todos dentro da escola são atores que devem participar do processo além de outros fora da escola e assim formar redes para que seja feito os corretos encaminhamentos quando necessário, os atores devem ser: saúde, segurança, educação, assistência social, juventude, garantia de direitos, conselhos municipais, famílias, os próprios alunos, educadores, funcionários da escola, gestores, técnicos, lideranças comunitárias, lideranças religiosas, conselheiros municipais, entre outros. Com o trabalho em conjunto das diferentes áreas de conhecimento é possível uma abordagem com maior efetividade.

\section{CONCLUSÃO}

A escola tem grande contribuição na formação dos cidadãos, pois a educação escolar oportuniza ao educando a formação de uma consciência crítica não só social e ambiental, mas também sobre a sua saúde. O período escolar é fundamental para trabalhar questões de promoção da saúde e prevenção as drogas, pois é nesse momento que, crianças e adolescentes, estão criando ou podem estar revendo seus hábitos e atitudes. 
Essa experiência proporcionou aos alunos da escola a oportunidade de articular os fundamentos teóricos e práticos sobre drogas e seus efeitos, refletidos durante as oficinas, desconstruindo preconceitos e estigmas sobre os usuários de drogas. Portanto, ela abre possibilidades de consolidar a parceria e avançar no estágio em Saúde Coletiva no espaço escolar com a temática das drogas, podendo indicar como salutar o trabalho de Educação e Saúde, fortalecendo a relação intersetorial como instrumento para tecer redes de cuidado. Cultivar uma relação de dialogicidade no contato com o outro no sentido de facilitar a formação de uma consciência crítica, capaz de identificar possíveis riscos.

Foi observada a necessidade de realizar trabalhos que deem continuidade ao que foi feito com os professores e funcionários, com o objetivo de fazê-los alcançar a autonomia na busca de promoção da saúde dos escolares. Para esse trabalho se necessita fazer parcerias com o Sistema de Saúde presente na comunidade, representado pela Unidade do Programa de Saúde da Família, para a realização de ações intersetoriais buscando a saúde desta comunidade.

\section{REFERÊNCIAS}

CASEMIRO, Juliana Pereira; FONSECA, Alexandre Brasil Carvalho da; SECCO, Fabio Vellozo Martins. Promoting health in school: reflections based on a review of school health in Latin America. Ciênc. saúde coletiva, Rio de Janeiro, v. 19, n. 3, p. 829-840, mar. 2014.

GIL, Hilda Luz Bolaños et al . Opiniões de adolescentes estudantes sobre consumo de drogas: um estudo de caso em Lima, Perú. Rev. Latino-Am.

Enfermagem, Ribeirão Preto, v. 16, n. spe, p. 551-

557, ago. 2008. Disponível em

$<$ http://www.scielo.br/scielo.php?script=sci_arttext\&pid=S0104-

$11692008000700008 \&$ Ing=pt\&nrm=iso $>$.

LEVY, Sylvain Nahum et al. Educação em saúde: histórico, conceitos e propostas. In: Educação em saúde: histórico, conceitos e propostas. Brasil. Ministério da Saúde, 1997.

MALTA, Deborah Carvalho et al. Prevalência do consumo de álcool e drogas entre adolescentes: análise dos dados da Pesquisa Nacional de Saúde Escolar. Rev bras epidemiol, v. 14, n. 1, p. 136-46, 2011. 
MARTINS, Mário Henrique da Mata; RIBEIRO, Maria Auxiliadora Teixeira. Repertórios linguísticos dos riscos industriais no Pontal da Barra, Maceió. Athenea Digital. Revista de pensamiento e investigación social, [S.I.], v. 16, n. 1, p. 139-158, mar. 2016.

MOREIRA, Fernanda Gonçalves; SILVEIRA, Dartiu Xavier da; ANDREOLI, Sérgio Baxter. Redução de danos do uso indevido de drogas no contexto da escola promotora de saúde. Ciência \& Saúde Coletiva, v. 11, n. 3, p. 807-816, 2006.

NASCIMENTO, Marcelo Oliveira do; AVALLONE, Denise De Micheli. Prevalência do uso de drogas entre adolescentes nos diferentes turnos escolares. Adolesc Saude. v.10, n.4, p.41-49, 2013.

SOARES, Cássia Baldini; JACOBI, Pedro Roberto. Adolescentes, drogas e AIDS: avaliação de um programa de prevenção escolar. Cadernos de Pesquisa, n. 109, p. 213-237, 2013.

TAVARES, Beatriz F.; BÉRIA, Jorge U.; LIMA, Maurício S. Prevalência do uso de drogas e desempenho escolar entre adolescentes. Rev Saúde Pública, v. 35 , n. 2, p. 150-8, 2001. 